\title{
PENGOLAHAN AIR HUJAN UNTUK KEBUTUHAN AIR BERSIH DENGAN METODE RAINWATER HARVESTING DI KAMPUNG KRANGKENG KABUPATEN SUMENEP
}

\author{
Cholilul Chayati ${ }^{1}$, Dani Andhika $\mathbf{P}^{2}$ \\ ${ }^{I}$ Prodi Teknik Sipil Universitas Wiraraja, cholilul@wiraraja.ac.id \\ ${ }^{2}$ Prodi Teknik Sipil Universitas Wiraraja, daniandhika@wiraraja.ac.id
}

\begin{abstract}
ABSTRAK
Kampung Krangkeng merupakan salah satu daerah yang sering mengalami kekeringan di waktu musim kemarau.kondisi ini membuat daerah tersebut mengalami krisis air bersih untuk memenuhi kabutuhan domestik sedangkan kondisi di kampung Krakeng tidak ada layanan air bersih PDAM untuk kebutuhanair bersih masyarakat kampung harus menggambil air bersih di sumber air yang terletak cukup jauh $\pm 2 \mathrm{~km}$ dari kampung krakeng.

Teknik Sistem pemanfaatan air hujan merupakan cara yang digunakan untuk mengumpulkan dan menyimpan air hujan dari atap rumah atau dipermukaan tanah pada saat hujan. Sebagai salah satu sumber air bersih, pemanfaatan air hujan dapat digunakan untuk mengatasi permasalahan kelangkaan air bersih, mengurangi volume limpasan air hujan dan mengisi kembali ke air tanah terutama di Kampung Krangkeng Dari hasil perhitungan didapat kebutuhan 52\% dari total kebutuhan air bersih di Desa Pasongsongan Kampung Krangkeng sebesar $5.212 \mathrm{~m}^{3} /$ tahun dengan standart kebutuhan air ratarata per hari sebesar 120 liter dan didapat volume bak penampungan air hujan (PAH) di Kampung Krangkeng sebesar $156 \mathrm{~m}^{3}$ dengan debit ketersediaan air $343 \mathrm{~m}^{3} /$ bulan untuk blok I, debit ketersediaan air $312 \mathrm{~m}^{3} /$ bulan untuk blok II, debit ketersediaan air $223 \mathrm{~m}^{3} /$ bulan untuk blok III.
\end{abstract}

Kata Kunci : Pengelolaan sumber daya air, sumber air bersih

\section{PENDAHULUAN}

\subsection{Latar Belakang}

Air adalah suatu kebutuhan pokok yang penting bagi manusia. Setiap manusia tidak akan lepas dari kebutuhan air. Sehingga ketersedian air harus dapat memenuhi kebutuhan seharihari, dengan cara memanfatakan menangkap air hujan melalui atap rumah warga.

Kampung Krakeng salah satu daerah yang ada kabupaten Sumenep dan merupakan salah satu daerah yang sering mengalami kekeringan karena sumber air yang terletak cukup jauh \pm $2 \mathrm{~km}$.

\subsection{Tujuan Khusus Penelitian}

1. Mengetahui debit air hujan yang dapat ditampung dalam memenuhi kebutuhan air bersih di Kampung Krakeng.

2. Mengetahui kebutuhan air bersih di Kampung Krankeng

3. Merencanakn desain kotruksi dan dimensi pengolahan air hujan (PAH) secara komunal di Kampung Krankeng 


\section{HASIL DAN PEMBAHASAN}

\subsection{Perhitungan Kebutuhan Air Baku}

Untuk menghitung kebutuhan air baku pada rumah tinggal digunakan standar SNI 037065-2005 untuk pemakaian kebutuhan air sesuai fungsi bangunan. Untuk rumah tinggal memiliki spesifikasi sebagai berikut :
1. Jenis bangunan
: Rumah tinggal
2. Lokasi
: Dusun Krankeng Kec. Pasongsongan
3. Jumlah Penduduk
: 119 Jiwa (Sumber : Data Kelurahan)
4. Total luasan atap rumah $: 1.293,875 \mathrm{~m}^{2}$

Berikut ini adalah contoh perhitungan luasan atap masing - masing areanya:

\section{Area Blok I (no 1 pada tabel 4.1)}
1. Panjang atap rumah
$: 10 \mathrm{~m}$
2. lebar atap rumah
$: 4 \mathrm{~m}$
3. Luas area atap
$:(10 \mathrm{~m} \times 4 \mathrm{~m}) / 0,8=50 \mathrm{~m}^{2}$

Tabel 1. Hasil Perhitungan Luas Tangkapan Air Hujan Keseluruhan

\begin{tabular}{|c|c|c|}
\hline No & Area & Area Luas atap (m2) \\
\hline 1 & Blok 1 & 631,719 \\
\hline 2 & Blok 2 & 575,625 \\
\hline 3 & Blok 3 & 410 \\
\hline \multicolumn{2}{|c|}{ Jumlah } & $1.617,344$ \\
\hline
\end{tabular}

(Sumber : Hasil Perhitungan Data 2019)

Berikut ini adalah contoh perhitungan kebutuhan air baku untuk rumah penduduk:

\section{Area Blok I}

Kebutuhan air rata - rata : 120 liter/org/hari.

Kebutuhan air baku perhari : jumlah penduduk x kebutuhan air rata-rata.

: 54 x 120 liter/hari

: 6.480 liter/hari.

: $6,48 \mathrm{~m}^{3} /$ hari.

Tabel 2. Hasil Perhitungan Kebutuhan Air

\begin{tabular}{|c|c|c|c|c|c|}
\hline No & Area & $\begin{array}{c}\text { Jumlah } \\
\text { penduduk } \\
\text { (org) }\end{array}$ & $\begin{array}{c}\text { Kebutuhan rata- } \\
\text { rata } \\
\text { (Liter/org/hari) }\end{array}$ & $\begin{array}{c}\text { Kebutuhan } \\
\text { air baku } \\
\text { total } \\
\text { (liter/hari) }\end{array}$ & $\begin{array}{c}\text { Kebutuhan } \\
\text { air baku } \\
\text { total } \\
\text { (m3/hari) }\end{array}$ \\
\hline 1 & Blok 1 & 54 & 120 & 6480 & 6,48 \\
\hline 2 & Blok 2 & 37 & 120 & 4440 & 4,44 \\
\hline 3 & Blok 3 & 28 & 120 & 3360 & 3,36 \\
\hline \multicolumn{2}{|c|}{ Jumlah } & 119 & 120 & 14280 & 14,28 \\
\hline
\end{tabular}

(Sumber : Hasil Perhitungan Data 2019) 


\section{NAROTAMA JURNAL TEKNIK SIPIL \\ e-ISSN: 2460-3430 \\ VOLUME 3 NOMOR 2 NOVEMBER 2019}

\subsection{Perhitungan Probabilitas Hujan Andalan}

Data hujan yang digunakan adalah dari tahun 2009 - 2018 (10 tahun). Dengan menggunakan Persamaan probabilitas hujan andalan dapat dihitung.

$\mathrm{P}(\%)=\left(\frac{m}{(n+1)}\right) \times 100 \%=\left(\frac{1}{(10+1)}\right) \times 100 \%=0.09 \%$

Tabel 3. Probabilitas Hujan Andalan

\begin{tabular}{|c|c|c|c|r|c|}
\hline \multirow{2}{*}{ Tahun } & $\begin{array}{c}\text { Curah } \\
\text { hujan }( \\
\text { mm/tahun) }\end{array}$ & No & $\begin{array}{c}|c| \\
\text { Curah } \\
\text { hujan }( \\
\text { mm/tahun })\end{array}$ & $\begin{array}{c}\text { Andalan } \\
(\%)\end{array}$ & Tahun \\
\hline 2009 & 519 & 1 & 2211,3 & 9,09 & 2013 \\
\hline 2010 & 2055 & 2 & 2055 & 18,18 & 2010 \\
\hline 2011 & 1243 & 3 & 1730,9 & 27,27 & 2017 \\
\hline 2012 & 1024,3 & 4 & 1631 & 36,36 & 2016 \\
\hline 2013 & 2211,3 & 5 & 1375,2 & 45,45 & 2014 \\
\hline 2014 & 1375,2 & 6 & 1243 & 54,55 & 2011 \\
\hline 2015 & 914 & 7 & 1064,9 & 63,64 & 2018 \\
\hline 2016 & 1631 & 8 & 1024,3 & 72,73 & 2012 \\
\hline 2017 & 1730,9 & 9 & 914 & 81,82 & 2015 \\
\hline 2018 & 1064,9 & 10 & 519 & 90,91 & 2009 \\
\hline
\end{tabular}

(Sumber : Hasil Perhitungan Data 2019)

Untuk mendapatkan curah hujan andalan dapat ditentukan langsung dengan memilih data hujan dengan probabilitas diatas $80 \%$ yang berada pada tahun 2015 dan 2019. Data hujan pada tahun tersebut tidak dapat mewakili keseluruhan data hujan lainnya dikarenakan masih ada data hujan dengan probabilitas yang lebih diatas $80 \%$

nilai rata-rata pada tahun yang memiliki nilai probabilitas lebih besar dari $80 \%$, sehingga nilai curah hujan andalan dipilih berdasarkan nilai yang mendekati nilai curah hujan rerata curah hujan peluang $80 \%$, dan $90 \%$ yaitu data tahun 2015, dan 2009 Kemudian dihitung curah hujan reratanya seperti pada perhitungan di bawah ini

$=\underline{\text { Curah hujan andalan }}$

$=\frac{271+0}{2}$

$=136 \mathrm{~mm} / \mathrm{bula}$ 


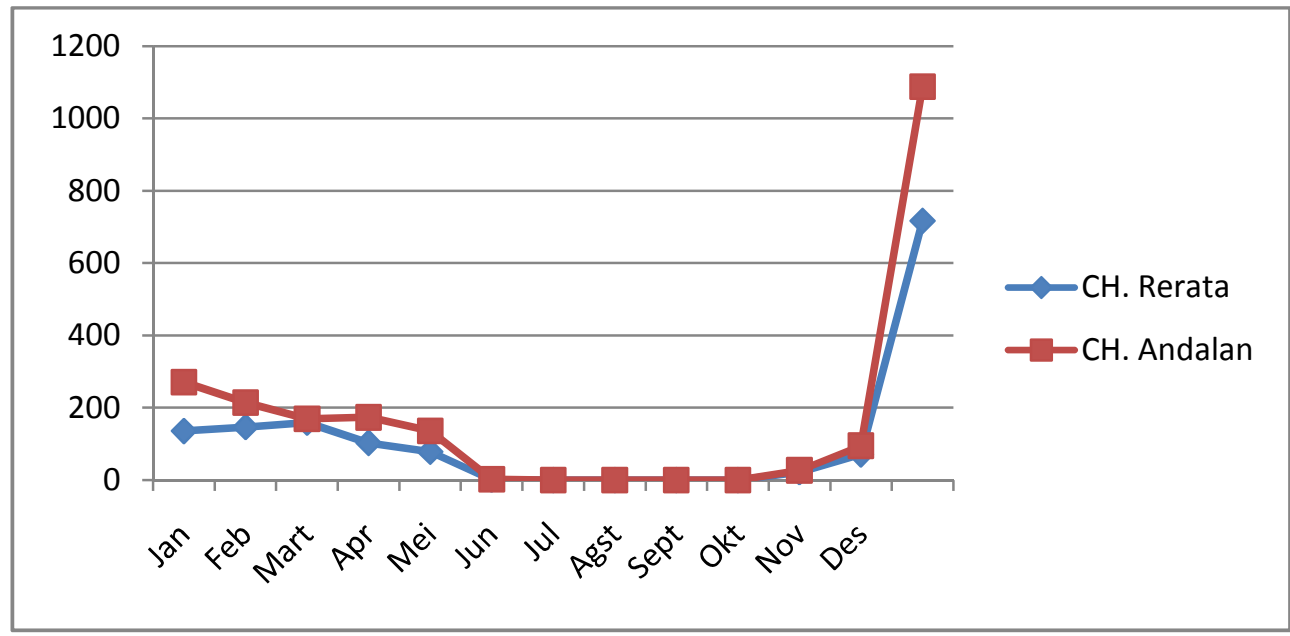

Gambar 1. Grafik Curah Hujan Andalan

(Sumber :Hasil Perhitungan Data 2019)

Dari grafik dapat dilihat curah hujan pada bulan Jun, Jul, Agustus, September, Oktober, November sangat kecil yaitu $<50 \mathrm{~mm} /$ bulan cenderung mengalami musim kemarau. Contoh perhitungan volume ketersediaan air untuk suplai bulan Januari pada seluruh pada area blok I yaitu sebagai berikut :

Total luasan atap (A) Koefisien run off $(\mathrm{C})$ : $631,719 \mathrm{~m}^{2}($ Tabel 4.1 Area blok I)

Volume air tertampung : 0,5 (Tabel 2.10)

: R x A x C (persamaan 2.4) $:(271 \times 10-3) \times 631,719 \times 0.5$ : $85,60 \mathrm{~m}^{3} /$ bulan.

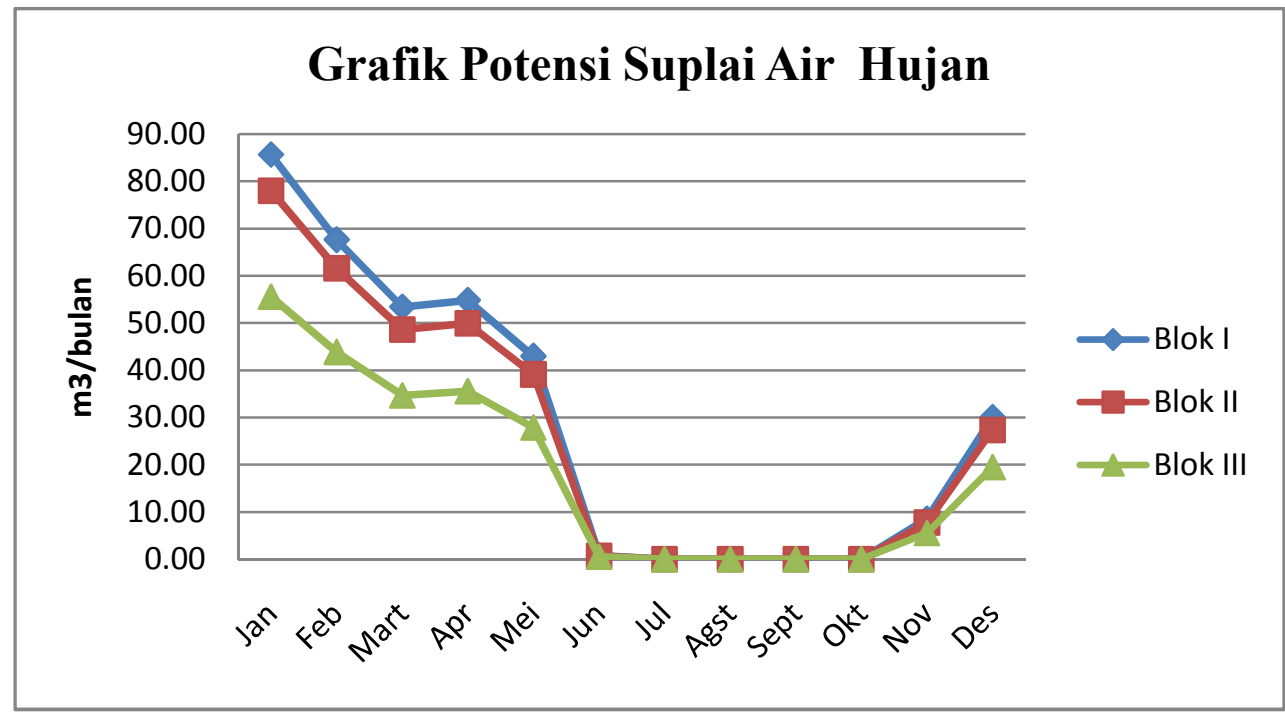

Gambar 2. Grafik Potensi Suplai Air Hujan (Sumber :Hasil Perhitungan Data 2019) 


\subsection{Perhitungan Persentase Ketersediaan Air Hujan Terhadap Kebutuhan Air Baku}

Contoh perhitungan rasio persentase volume ketersediaan air hujan terhadap kebutuhan air baku pada bulan Februari yaitu sebagai berikut :

Volume ketersediaan air hujan (c) : CH.And x Luas tang x Koef runoff (C)

$$
\text { : } 0,271 \times 631,719 \times 0,5=86 \mathrm{~m}^{3} / \text { bulan }
$$

Kebutuhan air baku (d) : Keb. air x Juml penduduk x Juml hari : $0,12 \times 54 \times 31=201 \mathrm{~m}^{3} /$ bulan

Rasio persentase $(\%)(\mathrm{e}) \quad:\left(\frac{c}{\mathrm{~d}}\right) \times 100$

$$
\begin{aligned}
& :\left(\frac{86}{201}\right) \times 100 \\
& : 43 \% \text {. }
\end{aligned}
$$

\begin{tabular}{|c|c|c|c|c|c|}
\hline Bulan & $\begin{array}{c}\text { Curah } \\
\text { Hujan } \\
\text { Andalan } \\
\text { (m3/bulan) }\end{array}$ & $\begin{array}{l}\text { Volume } \\
\text { Ketersedia } \\
\text { an Air } \\
\text { Hujan } \\
\text { (m3/bulan) }\end{array}$ & $\begin{array}{l}\text { Kebutuhan } \\
\text { Air Baku } \\
\text { (m3/bulan) }\end{array}$ & $\begin{array}{c}\text { Ketersediaan } \\
\text { Air Hujan } \\
\text { Terhadap } \\
\text { Kebutuhan } \\
\text { Air Baku } \\
(\%) \\
\end{array}$ & $\begin{array}{c}\text { Jumlah } \\
\text { Hari }\end{array}$ \\
\hline \multirow[t]{2}{*}{ (a) } & (b) & (C) & (d) & (e) & \multirow{2}{*}{ (f) } \\
\hline & $230 / 1000$ & $(\mathrm{bxAxC})$ & $(0,12 \times 54 \times f)$ & $(\mathrm{c} / \mathrm{d})$ & \\
\hline Jan & 0,271 & 86 & 201 & 43 & 31 \\
\hline Feb & 0,214 & 68 & 181 & 37 & 28 \\
\hline Mar & 0,169 & 53 & 201 & 27 & 31 \\
\hline Apr & 0,1735 & 55 & 194 & 28 & 30 \\
\hline Mei & 0,136 & 43 & 201 & 21 & 31 \\
\hline Jun & 0 & 0 & 194 & 0 & 30 \\
\hline Jul & 0 & 0 & 201 & 0 & 31 \\
\hline Aug & 0 & 0 & 201 & 0 & 31 \\
\hline Sep & 0 & 0 & 194 & 0 & 30 \\
\hline Okt & 0 & 0 & 201 & 0 & 31 \\
\hline Nov & 0,027 & 9 & 194 & 4 & 30 \\
\hline Des & 0,095 & 30 & 201 & 15 & 31 \\
\hline Total & 1,086 & 343 & 2365 & 14 & 365 \\
\hline
\end{tabular}

Tabel 4. Perbandingan Ketersediaan Air Hujan Terhadap Kebutuhan Air Baku di Area Rumah Blok

(Sumber :Hasil Perhitungan Data 2019) 
NAROTAMA JURNAL TEKNIK SIPIL

e-ISSN: $2460-3430$

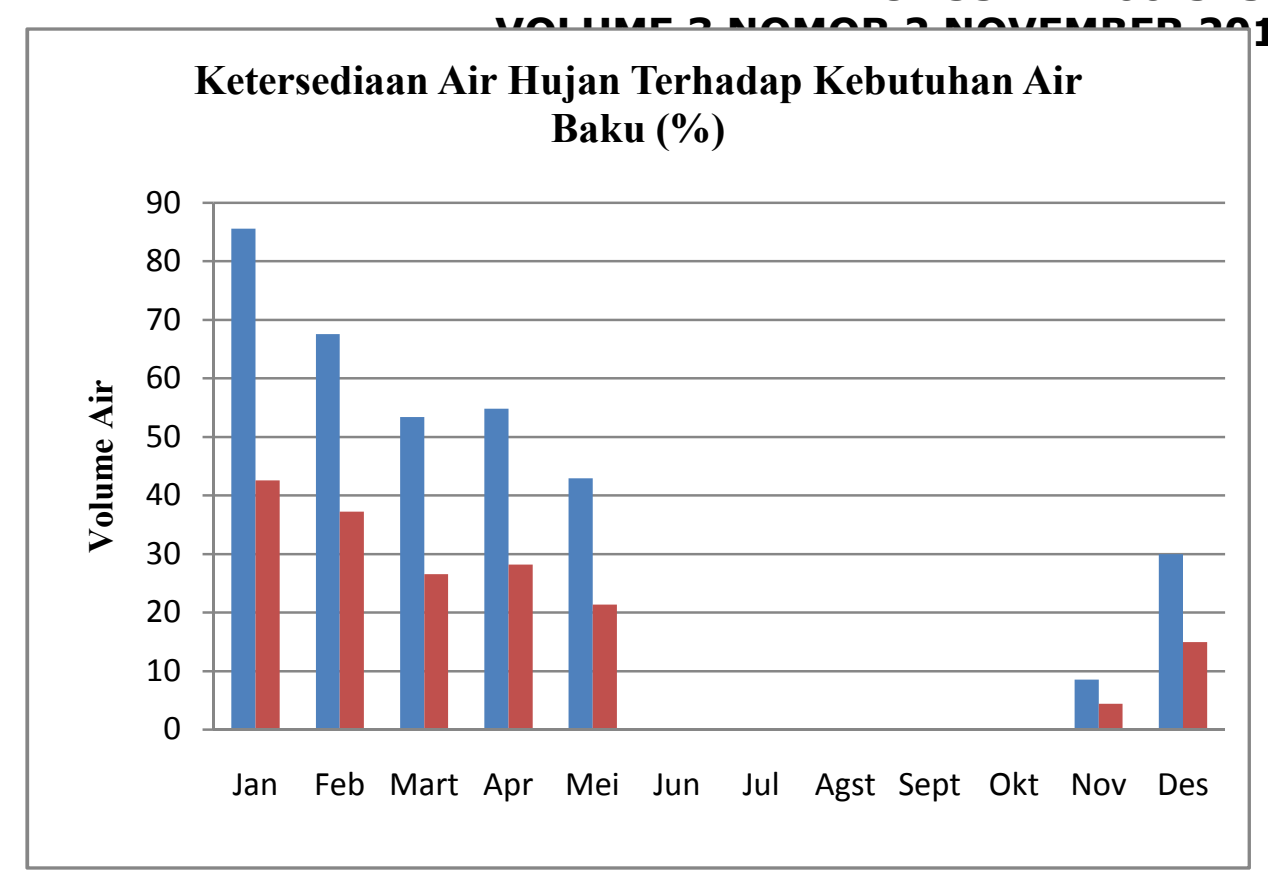

Gambar 3. Grafik Neraca Air Area Rumah Blok I

(Sumber :Hasil Perhitungan Data 2019)

ketersediaan air hujan terhadap kebutuhan air baku di Kampung Krankeng hanya mampu memenuhi $52 \%$ dari kebutuhan air baku.

- Area Blok I hanya mampu memenuhi kebutuhan air baku $14 \%$

- Area Blok II hanya mampu memenuhi kebutuhan air baku $19 \%$

- Area Blok III hanya mampu memenuhi kebutuhan air baku $18 \%$

\subsection{Perhitungan Kapasitas Penampungan Air Hujan (PAH)}

\section{a. Perhitungan Kapasitas PAH di Area Rumah Blok I}

perhitungan penampungan air hujan (PAH) berdasarkan suplai pada bulan Januari, Februari,Maret, April, Mei yang cenderung suplai air hujan tinggi

Volume PAH $=\frac{\text { Volume Suplai Air Hujan }}{5}$

$$
\begin{aligned}
& =\frac{86+68+53+55+43}{5} \\
& =61 \mathrm{~m}^{3^{5}}
\end{aligned}
$$

\section{b. Perhitungan Kapasitas PAH di Area Rumah Blok III}

Krangkeng Jadi perhitungan penampungan air hujan (PAH) berdasarkan suplai pada bulan Januari, Februari,Maret, April, Mei yang cenderung suplai air hujan tinggi 


\section{NAROTAMA JURNAL TEKNIK SIPIL \\ e-ISSN: 2460-3430 \\ VOLUME 3 NOMOR 2 NOVEMBER 2019}

Volume PAH $=\frac{\text { Volume Suplai Air Hujan }}{5}$

$$
\begin{aligned}
& =\frac{78+62+49+50+39}{5} \\
& =55 \mathrm{~m}^{3^{5}}
\end{aligned}
$$

\section{c. Perhitungan Kapasitas PAH di Area Rumah Blok III}

perhitungan penampungan air hujan (PAH) berdasarkan suplai pada bulan Januari, Februari,Maret, April, Mei r yang cenderung suplai air hujan tinggi

Volume PAH $=\frac{\text { Volume Suplai Air Hujan }}{5}$

$$
\begin{aligned}
& =\frac{56+44+35+36+28}{\mathrm{~m}^{3}} \\
& =40 \mathrm{~m}^{5}
\end{aligned}
$$

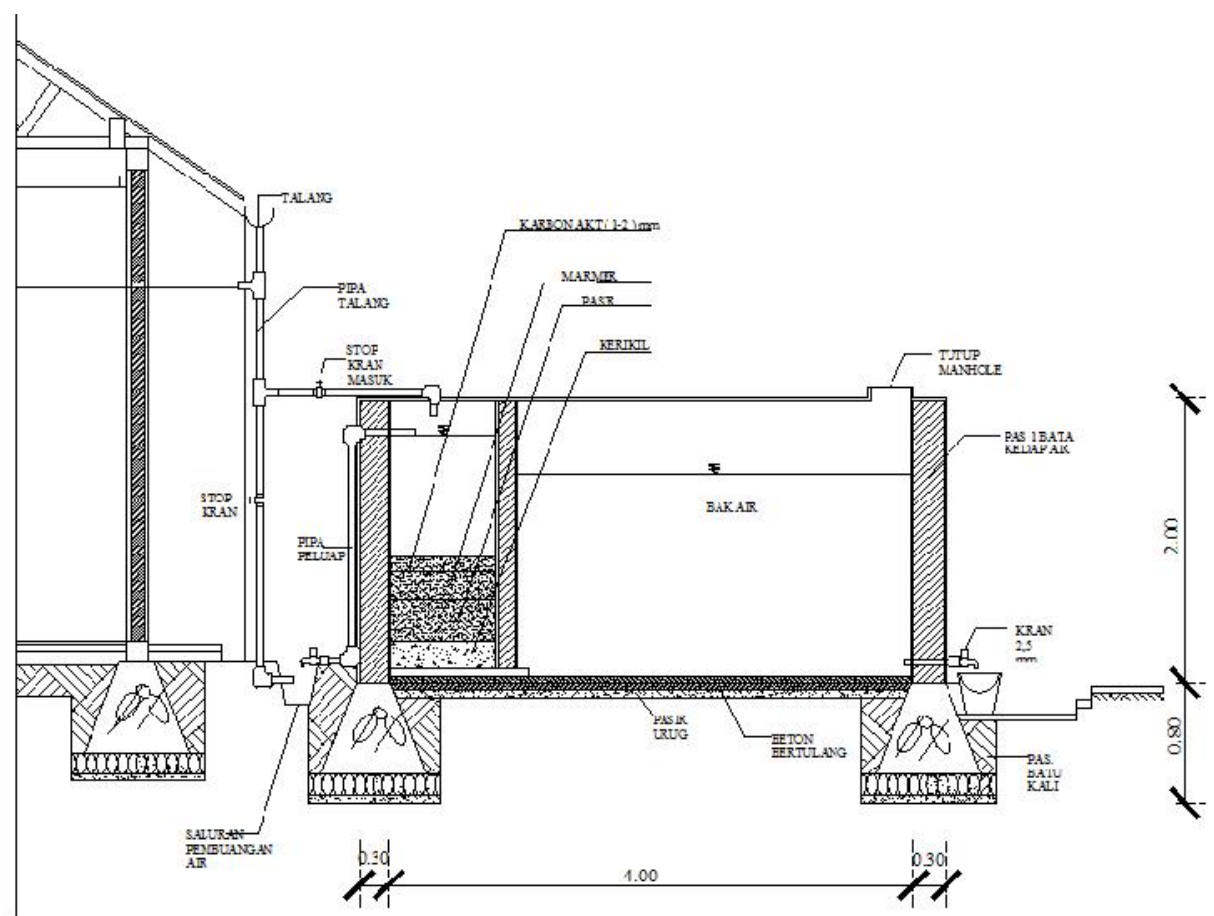

Gambar 4. konstruksi 1 BAK Penampungan Air Hujan 


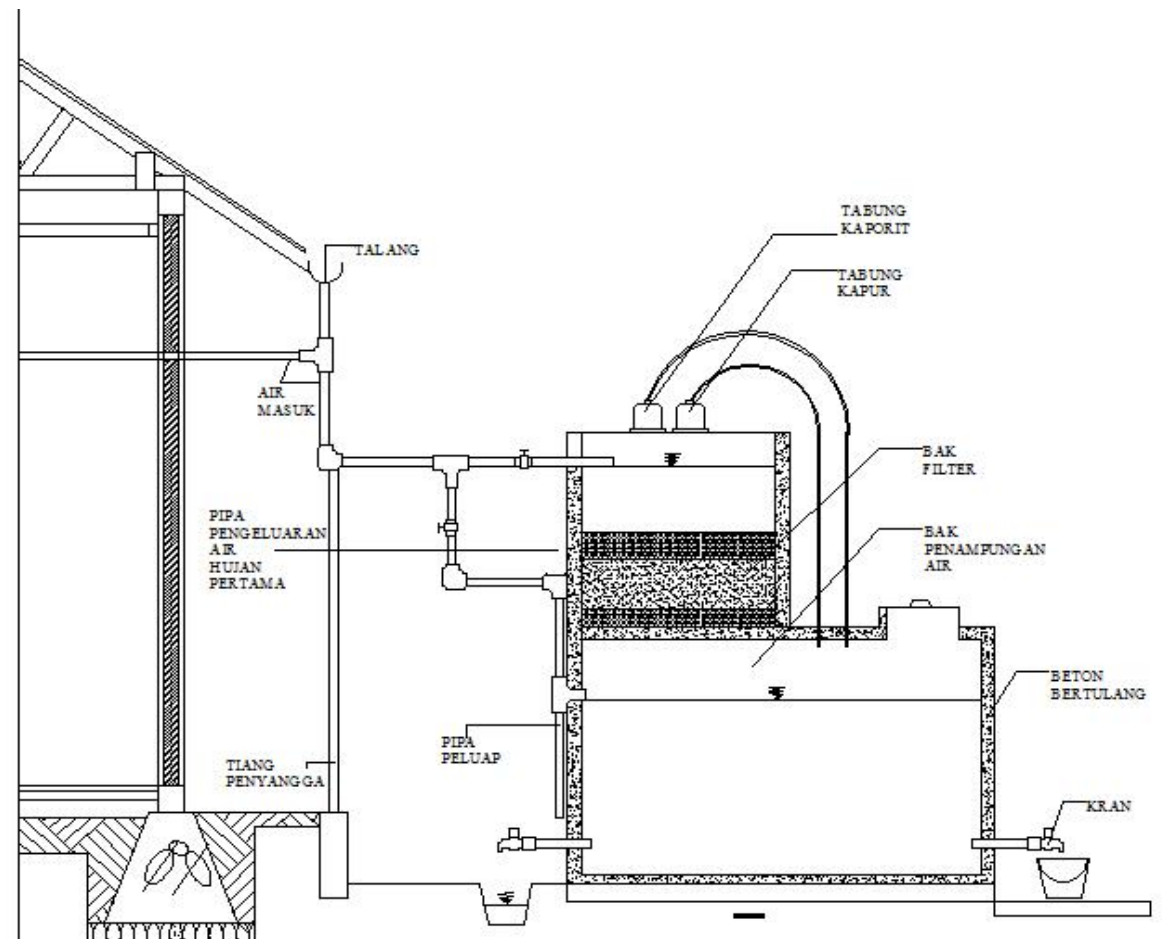

Gambar konstruksi 2 BAK Penampungan Air Hujan

\section{KESIMPULAN}

Berdasarkan hasil analisa dan data hasil penelitian kesimpulan sebagai berikut :

1. Jumlah debit kebutuhan air bersih di kampung Krankeng 14.280 Liter/hari atau 12,28 $\mathrm{m}^{3} /$ hari.

2. Jumlah total luasan daerah tangkapan air hujan (atap rumah) sebesar 1.617,344 $\mathrm{m}^{2}$ dengan kapasitas tampungan didapat dari blok pertama $61 \mathrm{~m}^{3}$, blok kedua $55 \mathrm{~m}^{3}$, blok ketiga 40 $\mathrm{m}^{3}$, debit yang dihasilkan sebesar $5.212 \mathrm{~m}^{3} /$ tahun dan bisa memenuhi $52 \%$ dari total air bersih.

3. Kontruksi pengolahan air hujan terdiri dari dua bagian yaitu bak pengendapan sekaligus bak saringan pertama dan bak penampung

Terima kasih kepada

DRPM untuk Dana Penelitian PDP tahun 2019

Nomor :113/SP2HL/LT/DRPM/2019/045/SP2H/LT/MONO/L7/2019 


\section{NAROTAMA JURNAL TEKNIK SIPIL \\ e-ISSN: 2460-3430 \\ VOLUME 3 NOMOR 2 NOVEMBER 2019}

\section{DAFTAR PUSTAKA}

1. Bambang Triatmodjo. 2010. “Hidrologi Terapan”,Yogyakarta:Beta Offset Yogyakarta

2. Dr. -Ing. Ir. Agus Maryono., 2017, “Memeanen Air Hujan”,Yogyakarta:Gadjah Mada University Press

3.Elgara, Rendra. 2012. “Alanalisis Potensi Pemanfaatan Air hujan”, (online) (https://nanopdf.com/download/bab-2-dasar-teori_pdf, diakses 12Februasi 2018).

4.Purnamasari. 2013. "Kriteria Perencanaan Teknis Sistem Distribusi Air Bersih", (online)(http://www.academica.edu/12888562/Kriteria_Perencanaan_Teknis_Sistem_Distri busi_Air_Bersih,diakses 12Februasi 2018).

5. Yulistyorini, Anie. 2011. "Pemanenan Air Hujan Sebagai Alternatif Pengolahan Sumber Daya Air di Perkotaan", (online) (file:///C:/Users/Asus/Downloads/3024-614-1PB.pdf,diakses 12Februasi 2018). 